\title{
Start-up of a Varspeed Group in Pump Mode, Practical Implementations and Tests
}

\author{
T. Maendly, A. Hodder, Member, IEEE, B. Kawkabani, Senior Member, IEEE
}

\begin{abstract}
The present paper addresses the practical implementation in a test bench of different control strategies for the start-up of a varspeed group in pump mode. In varspeed groups using a double-fed induction machine supplied by back to back voltage source inverters (VSI), the possibility exists of using the rotor side VSI to start up the group.

The current paper focuses on the start-up strategy and its implementation in a test bench of $3.3 \mathrm{kVA}$. After presenting the hardware composing the test bench, two different start-up strategies are detailed, which are the field oriented control and critical torque. Those two strategies are then implemented in practice, tested, measured and compared.
\end{abstract}

Index Terms - varspeed group, start-up, variable speed drives, control systems, double-fed induction machine, AC-DC power converters, field oriented control.

\section{NOMENCLATURE}

$S_{n} \quad$ rated apparent power in kVA

$u_{s}, u_{r} \quad$ voltage in per unit

$U_{n s}, U_{n r} \quad$ rated voltage in $\mathrm{V}$

$i_{s}, i_{r} \quad$ current in per unit

$I_{n s}, I_{n r}$

$i_{r d}, i_{r q}$

$r_{s}, r_{r}^{\prime}$

$x_{\sigma s}, x_{\sigma r}$

$x_{h}$

$x_{s}, x_{r}$

$\psi_{s}, \psi_{r}$

$f_{s}, f_{r}$

$f_{n}$

$\omega_{n}$

$p$

$t_{e m}$

$n$

$N_{n}$

$J$

$U_{D C}$

$u_{e}$

$T_{n}, T_{i}, T_{p E}$

rated current in $\mathrm{A}$

current in direct /quadrature axis in per unit resistance in per unit

leakage reactance in per unit

magnetizing reactance in per unit

stator and rotor reactance in per unit

flux in per unit

frequency in per unit

rated frequency in $\mathrm{Hz}$

rated pulsation in $\mathrm{rad} / \mathrm{s}$

number of pair of poles

electromagnetic torque in per unit

speed in per unit

rated speed in rpm

pump-turbine inertia in $\mathrm{kgm}^{2}$

DC-Link voltage in $\mathrm{V}$

DC-Link voltage in per unit

Note that the $s$ subscript is for stator and $r$ is for rotor.

\section{INTRODUCTION}

N owadays, the role of renewable energy resources becomes more important with the development of wind farms and solar energy. These types of power plants depend on the weather and the production of electricity does

T. Maendly, A. Hodder and B. Kawkabani are with the EPFL, Ecole Polytechnique Fédérale de Lausanne at the Electrical Machinery Group, CH-1015 Lausanne, Switzerland (phone: +41 216935609 , fax: +4121 69326 87, email: andre.hodder@epfl.ch, basile.kawkabani@epfl.ch). not necessarily match the time of the day when the consumers need this energy. Hence, variable speed pump-turbine units offer the possibility of absorbing the excess of energy produced by the renewable energy sources, store it and supply it when consumers need it. The advantages of variable speed units compared to constant speed units are mainly the improved efficiency under partial loads, the flywheel effect and the increased network stability in the presence of faults.

Several studies addressing the modeling and analysis of variable speed pump-turbine units have been presented, either on the hydraulic part or on the electrical part [1]-[11].

The varspeed group addressed in the present paper uses a double-fed induction machine with a rotor cascade composed of a transformer and back-to-back Voltage Source Inverters, as shown in Fig. 1 and detailed in [12].

In standard operating mode, the varspeed control is divided in two parts, a transformer part and a machine part, as shown in Fig. 1. The transformer part maintains the DC-Link voltage at a constant value and also acts as a Static Var Compensator (SVC), whereas the machine part controls the speed of the machine as well as the stator reactive power.

Usually, the start-up of varspeed groups requires external equipment such as a transformer or another motor.

In the case of starting up without external equipment, the stator of the machine is short-circuited and the rotor cascade is used to supply the rotor. At that moment the transformer part still keeps the voltage constant, whereas the machine part is controlled such as to produce the maximum start-up torque.

For the start-up, no water is present in the runner and the remaining torque, including friction losses, ventilation losses and bearing losses, is a few percent of the rated torque.

The rotor cascade is usually sized to allow a speed variation of about $10 \%$ around the rated speed. Therefore, due to the slip power, only $10 \%$ of the rotor rated voltage is required, whereas the current is the rated one. This is due to the fact that the voltage is the limiting factor in a VSI.

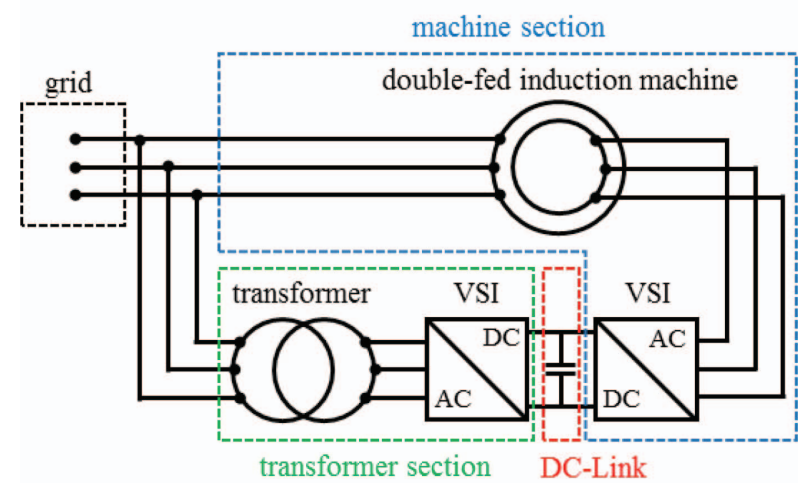

Fig. 1. Complete model of the variable speed unit. 
The consequence of this quite low voltage present in the back-to-back converter is that control strategies have to be set up to maximize the torque.

Different studies where a field-oriented control is used have been performed [13]-[16].

The present paper addresses the practical implementation of start-up strategies, in a test bench of $3.3 \mathrm{kVA}$.

The paper first details the hardware composing the bench and then, two different control strategies are presented which are the field oriented control and the critical torque.

Those strategies are explained in theory and are then tested and measured on the bench.

Finally, a comparison between the two control strategies is presented.

\section{THE TEST BENCH}

The test bench used in this paper is composed of a $3.3 \mathrm{kVA}$ double-fed induction machine and of a DC machine as shown in Fig. 2. The DC machine is used as a load (positive or negative), but is useless in the study on the startup strategies.

An additional inertia is also present on the shaft. The purpose of this inertia is to slow down the transient phenomenon to be able to analyze them in a better way. Moreover, the additional inertia increases the friction losses to simulate the few percent present in a real installation.

The main parameters of the test bench are given in TABLE 1 .

The double-fed induction machine is $3.3 \mathrm{kVA}$, $380 \mathrm{~V} / 92.7 \mathrm{~V}, 1500 \mathrm{rpm}$.

The rotor cascade is constituted of the transformer, two 2level VSIs and a capacitor bank for the DC-link.

As explained earlier, the transformer side VSI is used as a controlled rectifier to supply the DC-Link. The details of the behavior of the transformer part are outside of the scope of this paper. For further explanations and details refer to [12].

The VSIs are controlled by Digital Signal Processors (DSP), which are Texas Instrument F28069ISO and measurements of voltages and currents are of course put to scale and shaped up to match the analog inputs of the DSP. Note that a 12 bits position sensor is used for the measurement of the mechanical angle and of the speed.

Fig. 3 shows the transformer, the capacitor bank, the two converters and the control electronics with the DSP.

\section{START-UP OF THE VARSPEED}

The whole start-up procedure consists in short-circuiting the stator of the machine, supplying the rotor to reach a given speed, then synchronizing the machine to the grid and launching the main control, which runs during the standard operating mode.

\section{A. Start-up study}

To be able to synchronize with the grid, the varspeed must reach a minimal speed of about 0.9 per unit [13]. A real varspeed group is then equipped with an automatic switch to synchronize the machine to the grid. Currently the test bench has only a switch manually turned on and off. The study of this paper is only focused on how to reach the minimal speed required for synchronization. The control implemented in the test bench is then adapted to maintain the speed constant, allowing a manual synchronization of the varspeed.

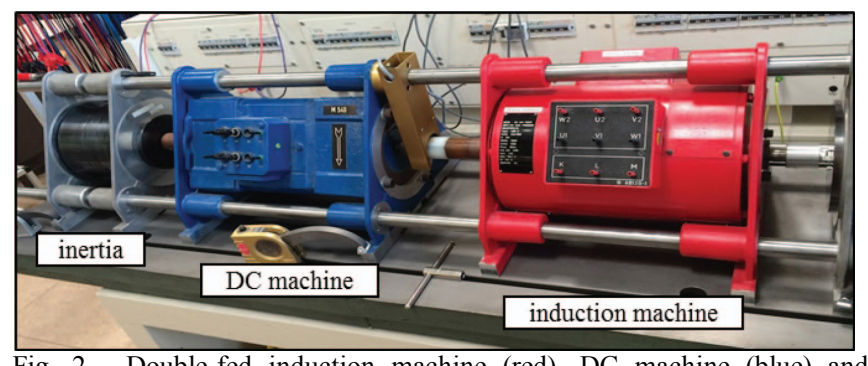

Fig. 2. Double-fed induction machine (red), DC machine (blue) and additional inertia composing the test bench.

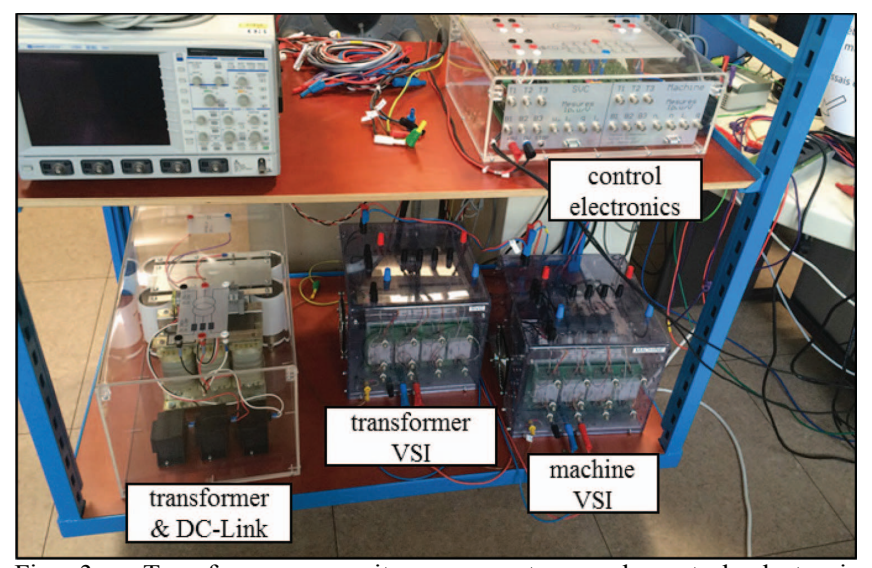

Fig. 3. Transformer, capacitors, converters and control electronics composing the test bench.

TABLE 1

Main Rated VAlues of THE VARSPEed

\begin{tabular}{ccc}
\hline \hline Symbol & Value & Unit \\
\hline$N_{n}$ & 1500 & rpm \\
$S_{n}$ & 3.3 & kVA \\
$U_{n s}$ & 380 & $\mathrm{~V}$ \\
$U_{n r}$ & 92.7 & $\mathrm{~V}$ \\
$I_{n s}$ & 5 & $\mathrm{~A}$ \\
$I_{n r}$ & 15.1 & $\mathrm{~A}$ \\
$f_{n}$ & 50 & $\mathrm{~Hz}$ \\
$2 p$ & 4 & - \\
$r_{s}$ & 0.1 & per unit \\
$x_{\sigma s}$ & 0.12 & per unit \\
$x_{h}$ & 2.34 & per unit \\
$x_{\sigma r}$, & 0.12 & per unit \\
$r_{r}{ }^{\prime}$ & 0.075 & per unit \\
$J$ & 0.34 & kgm ${ }^{2}$ \\
$U_{D C}$ & 70 & $\mathrm{~V}$ \\
$T_{e}$ & $0.000{ }^{\prime} 25$ & $\mathrm{~s}$ \\
\hline \hline
\end{tabular}




\section{B. Start-up strategies}

Two start-up strategies are implemented in the bench and briefly described in this section.

\section{1) Field oriented control}

One way of controlling an induction motor is by acting on the stator current real and imaginary components [14]. By using the Park transformation with a reference frame locked on the rotor flux, the real and imaginary components of the current allow to control the flux, respectively the electromagnetic torque.

This method is called the Field Oriented Control (FOC) and has the advantage of having a good dynamic behavior.

\section{2) Critical torque}

Fig. 4 shows the equivalent scheme of an induction machine and Fig. 5 shows the same scheme modified using the Thevenin's theorem [15].

Once the parameters of an induction machine are known, the torque characteristic can be determined, as shown in Fig. 6. This characteristic depends on the amplitude and frequency of the supply voltage. It is therefore possible to apply the adequate voltage and frequency to have the critical torque, at every speed.

This method will be called the Critical Torque (CT).

\section{Power limitation during the start-up}

From the machine side, the start-up is expected to be as fast as possible. This is done by applying the maximal torque on the machine, regardless of the power consumed.

In practice, the transformer part is taken into account because the start-up power is delivered through it. Additional limitations are added in the start-up control so that the transformer in the rotor cascade always works in its operating range. These limitations are not detailed in this paper.

\section{START-UP PROCEDURE WITH FIELD ORIENTED CONTROL}

The basic equations describing an induction machine are the following:

$$
\begin{aligned}
& \underline{u}_{s}=r_{s} \underline{i}_{s}+j f_{s} \underline{\psi}_{s}+\frac{1}{\omega_{n}} s \underline{\psi}_{s} \\
& \underline{u}_{r}=r_{r}^{\prime} \underline{i}_{r}+j f_{r} \underline{\psi}_{r}+\frac{1}{\omega_{n}} s \underline{\psi}_{r} \\
& \underline{\psi}_{s}=x_{s} \underline{i}_{s}+x_{h} \underline{i}_{r} \\
& \underline{\psi}_{r}=x_{r} \underline{i}_{r}+x_{h} \underline{i}_{s} \\
& t_{e m}=\operatorname{Im}\left[\underline{\psi}_{s}^{*} \underline{i}_{s}\right]
\end{aligned}
$$

With:

$$
\begin{aligned}
& x_{s}=x_{h}+x_{\sigma s} \\
& x_{r}=x_{h}+x_{\sigma r}^{\prime}
\end{aligned}
$$

The total leakage coefficient is defined as:

$$
\sigma=1-\frac{x_{h}^{2}}{x_{s} x_{r}}
$$

The supply voltage is built by the VSI from the DC-Link. The voltage seen by the rotor of the induction machine is:

$$
u_{e}=\sqrt{\frac{2}{3}} \frac{U_{D C}}{2 U_{n r}}
$$

This voltage represents, in per unit, the voltage of the DCLink in the rotor reference frame. This voltage is used to size the regulators.

\section{A. Characteristics of the system to control}

It is important to first clarify that in the case of the varspeed, the stator is short-circuited and the rotor is supplied. Even though the rotor FOC method is applied, it physically acts on the stator flux of the machine.

From (1), one has :

$$
s \underline{\psi}_{s}=\omega_{n}\left(-r_{s} \underline{i}_{s}-j f_{s} \underline{\psi}_{s}\right)
$$

As the stator is short-circuited, the voltage $u_{s}$ is equal to 0 . Replacing $i_{s}$ from (4), one can rewrite (10) as :

$$
s \underline{\psi}_{s}=-\left(\frac{1}{T_{s}}+j f_{s} \omega_{n}\right) \underline{\psi}_{s}+\frac{x_{h}}{T_{s}} \underline{i}_{r}
$$

With :

$$
T_{s}=\frac{x_{s}}{\omega_{n} r_{s}}
$$

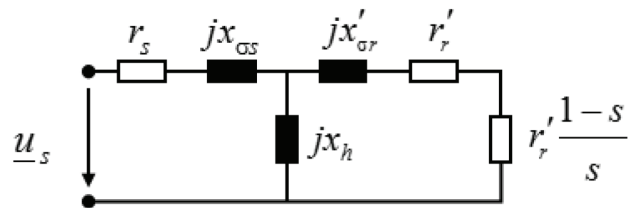

Fig. 4. Equivalent scheme of one phase of an induction machine.

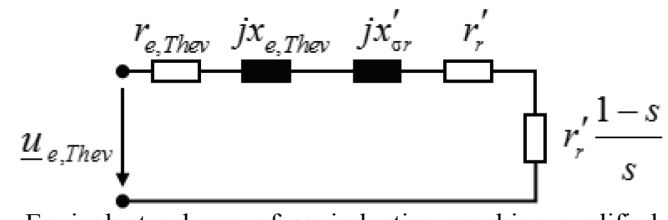

Fig. 5. Equivalent scheme of an induction machine modified using the Thevenin's theorem.

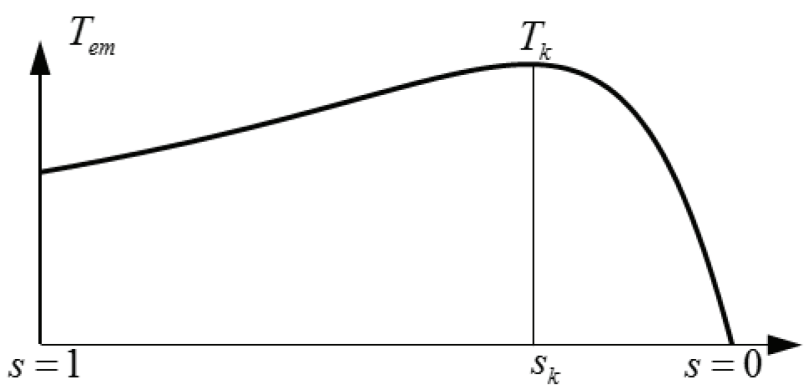

Fig. 6. Torque characteristic of an induction machine with its critical torque and slip. 
As the control is oriented on the stator flux, this latter one is purely real :

$$
\underline{\psi}_{s}=\psi_{s d}=\psi_{s} \quad \psi_{s q}=0
$$

Taking the stator flux as reference frame, the rotor current $\underline{i}_{r}$ can be decomposed as :

$$
\underline{i}_{r}=i_{r d}+j i_{r q}
$$

From (11) and (14) one has :

$$
\begin{aligned}
& s \psi_{s}=-\frac{1}{T_{s}} \psi_{s}+\frac{x_{h}}{T_{s}} i_{r d} \\
& 0=-f_{s} \omega_{n} \psi_{s}+\frac{x_{h}}{T_{s}} i_{r q}
\end{aligned}
$$

In steady state condition, the stator flux is determined with (15) :

$$
\psi_{s}=x_{h} i_{r d}
$$

From (5) and (17), the electromagnetic torque is given by:

$$
t_{e m}=\frac{x_{h}}{x_{s}} \psi_{s} i_{r q}
$$

Equation (17) shows that in the chosen reference frame, $\psi_{s}$ depends only on the real component of the rotor current. By applying a constant stator flux, (18) shows that the electromagnetic torque can be controlled using only the imaginary part of the rotor current.

However, the angles of the stator and rotor current phasors have to be determined to decompose the current in direct axis and quadrature axis. These angles are determined by computing the stator and rotor frequencies.

The stator frequency $f_{s}$ can be computed from (16) :

$$
f_{s}=\frac{x_{h}}{\omega_{n} T_{s}} \frac{i_{r q}}{\psi_{s}}
$$

The rotor frequency is used in the regulators and is determined by :

$$
f_{r}=f_{s}-f_{m}
$$

Where $f_{m}$ is the mechanical frequency and is equal to the speed expressed in per unit.

The rotor and stator angles needed in the Park transformations [14] are then computed as follow :

$$
\begin{aligned}
& \theta_{s}=\theta_{s}+\omega_{n} f_{s} T_{e} \\
& \theta_{r}=\theta_{s}+p \theta_{m}
\end{aligned}
$$

\section{B. Regulators}

With the machine parameters known (1)-(7), a classical cascaded control is applied, as shown in Fig. 7. A PI multivariable is used to control the current whereas a standard PI regulator is used to control the stator flux.

Every controlled value is filtered, so the values of the filters are taken into account in the regulators parameters. The filters time constants are determined experimentally.

\section{1) Rotor current regulator}

The multivariable PI regulator for the rotor current is sized using the Magnitude Criterion [17]. The time constants are given by :

$$
\begin{aligned}
& T_{n, i}=\frac{\sigma x_{r}}{\omega_{n} r_{t}} \\
& T_{i, i}=\frac{2 u_{e} T_{p E i}}{r_{t}}
\end{aligned}
$$

With :

$$
r_{t}=r_{r}^{\prime}+r_{s}\left(x_{h} / x_{s}\right)^{2}
$$

And $T_{p E i}$ the small time constant of the system :

$$
T_{p E i}=T_{\text {filt }, i}+T_{e} / 3
$$

Where $T_{\text {filt }, i}=0.002 \mathrm{~s}$ is the time constant of the current filter and $T_{e}$ is the sampling period.

\section{2) Stator flux regulator}

The PI regulator for the stator flux is also sized using Magnitude criterion. Its time constants are :

$$
\begin{aligned}
& T_{n, \psi}=\sigma T_{s} \\
& T_{i, \psi}=2 x_{h} T_{p E \psi}
\end{aligned}
$$

With :

$$
T_{p E \psi}=T_{f i l t, \psi}+T_{p E i}
$$

The time constant of the filter is $T_{\text {filt }, \psi}=0.005 \mathrm{~s}$.

\section{3) Speed regulator}

As mentioned in paragraphs IV.A and IV.B, the synchronization speed has to be maintained to allow the manual synchronization to the grid. An additional speed regulator is added in cascade to the quadrature current control. This regulator is only activated when the synchronization speed is reached.

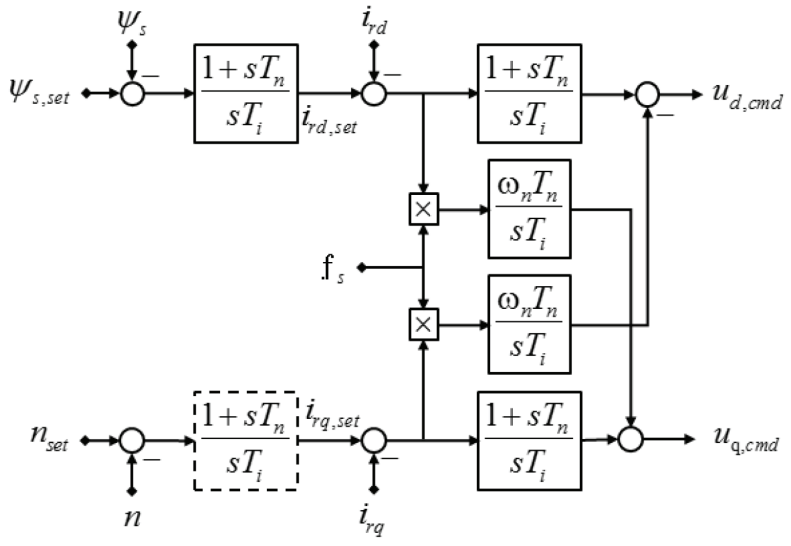

Fig. 7. Cascaded control. 


\section{Start-up steps}

To reach that minimal speed, the start-up is composed of 3 steps, depending on the speed of the machine. The set values of these steps are summarized in TABLE 2.

The first step starts with the magnetization of the machine. The stator flux set value is applied $1 \mathrm{~s}$ before the rotor current set value is reached.

Passing from one step to the other is done when a given speed is reached $\left(\mathrm{n}_{\max 1}, \mathrm{n}_{\max 2}\right)$. Those speeds depend on the machine parameters and the DC-Link voltage :

$$
\begin{aligned}
& n_{\max 1}=\sqrt{\frac{1}{\left(x_{r} / x_{h}\right)^{2}+\left(\sigma x_{r}\right)^{2}}} u_{e} \\
& n_{\max 2}=\frac{u_{e}}{\sqrt{2} \cdot \sigma x_{r}}
\end{aligned}
$$

\section{Start-Up Procedure With the CRITICAL TORQUE METHOD}

As presented in paragraph IV.B.2, the CT method uses the machine parameters. The equivalent voltage and impedance from the Thevenin's theorem shown in Fig. 5 are computed as :

$$
\begin{aligned}
& u_{e, \text { Thev }}=u_{s} \frac{j x_{h}}{r_{s}+j x_{s}} \\
& z_{e, \text { Thev }}=r_{e, \text { Thev }}+j x_{e, \text { Thev }}=j x_{h} \frac{\left(r_{s}+j x_{\sigma s}\right)}{r_{s}+j x_{s}}
\end{aligned}
$$

\section{A. Determination of the supply frequency}

The frequency of the voltage applied on the rotor is chosen to have the maximal torque (see Fig. 6). This frequency depends on the speed of the machine.

The critical slip is given by:

$$
s_{k}=\frac{r_{r}^{\prime}}{\sqrt{r_{e, \text { Thev }}^{2}+\left(x_{e, \text { Thev }}+x_{\sigma r}^{\prime}\right)^{2}}}
$$

As the varspeed is supplied through its rotor, the expression of the slip is :

$$
s=\frac{f_{r}-f_{m}}{f_{r}}
$$

From (35), expressing the mechanical frequency $f_{m}$ as the product of the speed in per unit and the nominal frequency, the supply frequency is computed as follow :

$$
f_{\text {start }-u p}=-\frac{n f_{n}}{1-s_{k}}
$$

Note that, as the reactances depend on the frequency, they have to be recomputed at every control loop, according to equation :

$$
x_{\text {start-up }}=x_{n} \frac{f_{\text {start-up }}}{f_{n}}
$$

TABLE 2

START-UP STEPS

$\underline{\text { Step } 1: \text { Rated torque and flux }}$

$\left(0<n<n_{\max 1}\right)$

$$
\begin{aligned}
& \psi_{s, s e t}=1 \\
& i_{r q, s e t}=-1
\end{aligned}
$$

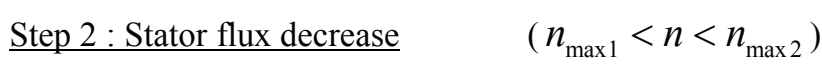

$$
\begin{aligned}
& \psi_{s, s e t}=-\frac{x_{h}}{x_{r} f_{r}} \sqrt{u_{e}^{2}-\left(\sigma x_{r} f_{r}\right)^{2}} \\
& i_{r q, s e t}=-1
\end{aligned}
$$

Step 3 : Optimization of the rotor current

$$
\left(n_{\max 2}<n\right)
$$

$$
\begin{aligned}
& \psi_{s, s e t}=-\frac{x_{h}}{\sqrt{2} x_{r} f_{r}} u_{e} \\
& i_{r q, s e t}=\frac{u_{e}}{\sqrt{2} \sigma x_{r} f_{r}}
\end{aligned}
$$

\section{B. Determination of the supply voltage amplitude}

As the torque is proportional to the square of the voltage amplitude, the maximum voltage is chosen, remaining in the operating range of the machine. So the voltage amplitude is determined to have 1 per unit of current :

$$
u_{\text {start-up }}=z_{\text {equ }} i_{\text {rotor }}=z_{\text {equ }}
$$

Where $z_{\text {equ }}$ is the norm of the equivalent impedance of the machine computed from Fig. 4.

\section{Start-up Steps}

Looking at (36), when the machine is at standstill, the supply frequency is 0 , which correspond to a DC supply voltage. But the machine can obviously not start up with DC voltage.

One way to avoid this problem is to give the machine an impulsion by applying a voltage with a small frequency.

For the test bench, a voltage of $10 \mathrm{~Hz}$ and 0.2 per unit of amplitude is sufficient to start up the machine. After 1s, the calculation of amplitude and frequency start-up and the CT is applied.

Note that when the synchronization speed is reached, as the synchronization is not automatic, a voltage with constant amplitude and frequency is applied to maintain the speed until the user synchronizes the varspeed to the grid. These amplitude and frequency are determined experimentally and are not present in a real varspeed with automatic synchronization. 


\section{MEASUREMENTS}

This section presents the start-up measurements of the varspeed described in section IV.

\section{A. Field Oriented Control Start-up}

Fig. 8 shows the varspeed start-up, starting at 0s and finishing at about $15 \mathrm{~s}$.

The rotor current $i_{r d}$ is in red and $i_{r q}$ is in blue. The currents are in per unit, referenced to the left y-axis. The speed (in black) is also in per unit referenced to the right yaxis.

Looking first at $i_{r d}$, one can observe the magnetization step from $0 \mathrm{~s}$ to $1 \mathrm{~s}$, while the quadrature current is null. The direct current remains constant until 4s, after what it slowly decreases. This shows the transition from step 1 to step 2 of the start-up. The value of the current during step 1 corresponds to a nominal stator flux, according to (17).

After $1 \mathrm{~s}$, the quadrature current is set to -1 per unit, which apply the maximal electromagnetic torque. As a reminder, the minus sign is needed to turn in the correct direction, knowing the supply comes through the rotor and not the stator. The decrease of the quadrature current after $1 \mathrm{~s}$ is due to the limitation of the power delivered by the transformer part, as mentioned in paragraph IV.C.

The sudden positive peak of current at around $15 \mathrm{~s}$ is due to the activation of the speed regulator (paragraph V.B.3) added to maintain constant speed until manual synchronization.

As the transformer of the test bench is oversized, compared to a real varspeed unit, the speed $n_{\max 2}$ is not reached. This means that the third start-up step is not required for the test bench.

\section{B. Critical Torque Start-up}

Fig. 9 shows the varspeed start-up using the CT method. The start-up starts at $0 \mathrm{~s}$ and finishes at around $26 \mathrm{~s}$.

The speed of the machine in blue and the supply frequency in red are referenced to the left y-axis and the amplitude of the supply voltage in green is referenced to the right y-axis.

The impulsion given to the machine is clearly visible by looking at the constant frequency between 0 s and 1s. After that, the critical slip is computed and applied to the machine.

The amplitude of the supply voltage is limited by the power delivered by the transformer.

\section{Comparison between both methods}

The two methods allow the machine of the test bench to reach the minimal speed required to sync the varspeed to the grid.

The FOC method has much better dynamic performances as it takes about $40 \%$ less time than the CT method to start up the varspeed group.

In the CT method, the flux is not optimized. This is probably one of the major reasons for the discrepancies in terms of performance between the CT and FOC methods.

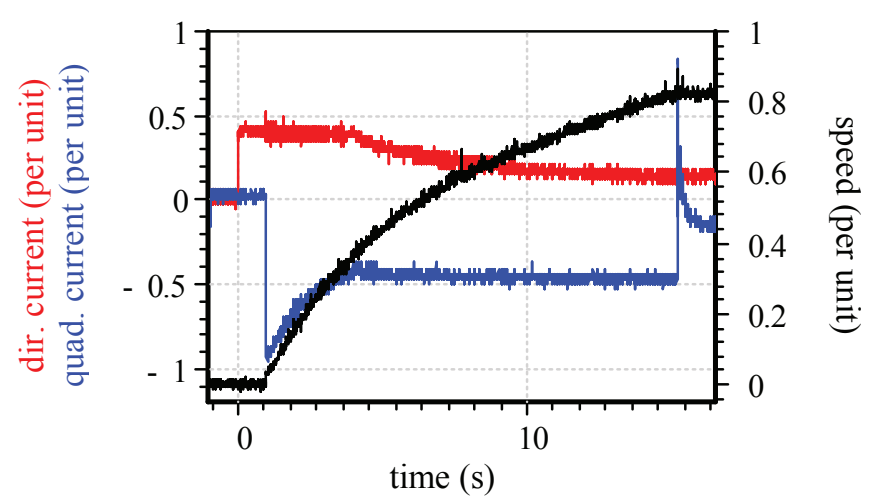

Fig. 8. Rotor currents and speed of the varspeed.

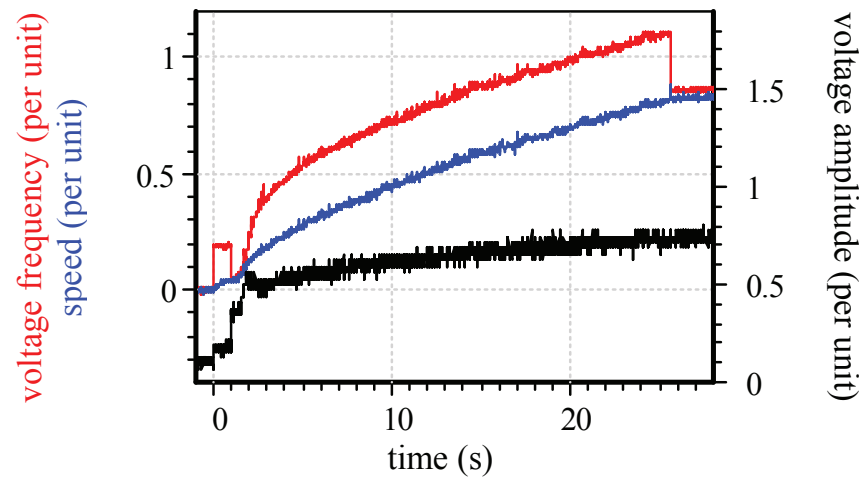

Fig. 9. Speed of the varspeed and amplitude and frequency of the supply voltage with the critical torque start-up method.

Actually, during the start-up with the CT method, the voltage applied, in terms of amplitude and frequency, will probably apply a flux higher than the nominal flux, resulting in the saturation of the iron core and decreased performances.

However, the FOC method requires the design of complex controls in cascade, while the CT method uses only basic equations of the induction machine. In that sense, the FOC method requires much more computing power.

Finally, if the FOC method is theoretically proven for real size varspeed, it is not sure that the CT method is sufficient to start up the machine with a non-oversized transformer.

\section{CONCLUSION}

After recalling the basics of a varspeed group composed of a double-fed induction machine supplied by a back to back VSI converter, the present paper presented the start-up principle using the rotor side VSI.

Then, two different start-up strategies which are the Field Oriented Control and the Critical Torque, have been detailed and implemented in the bench.

The measurements show that, as expected the Field Oriented Control offers a faster start-up, with the drawback of requiring more computing power.

The bench developed allows an easy test of start-up strategies, and other strategies should be tested in the future to find the best one for the start-up of a varspeed group. 


\section{REFERENCES}

[1] Y. Pannatier, B. Kawkabani, G. Sari, J.-J. Simond, "Stability Studies of a Mixed Islanded Power Network with Varspeed Units using Simplified Models of the Converters", Energy Conversion Congress and Expositon (ECCE), Atlanta, GA, Sept 12-16, 2010.

[2] J. Janning, A. Schwery, "Next generation variable speed pump-storage power stations", $13^{\text {th }}$ European Conference on Power Electronics and Application, Barcelona, Spain, Sept 8-10, 2009.

[3] T. Kuwabara, A. Shibuya, H. Furuta, E. Kita, K. Mitsuhashi, "Design and dynamic response characteristics of $400 \mathrm{MW}$ adjustable speed pumped storage unit for Ohkawachi power station", IEEE Transactions on Energy Conversion, vol. 11, issue 2, pp. 376-384, June, 1996.

[4] J. Fraile-Ardanuy, J. R. Wilhelmi, J. J. Fraile-Mora, J. I. Pérez, "Variable-speed hydro generation: operational aspects and control", IEEE Transactions on Energy Conversion, vol. 21, issue 2, pp. 569574, June, 2006.

[5] K. Grotenburg, F. Koch, I. Erlich, U. Bachmann, "Modeling and dynamic simulation of variable speed pump storage unit incorporated into the German Electric Power System”, EPE 2001, Graz, Austria, 2001.

[6] E. Kopf, S. Brausewetter, M. Giese, F. Moser, "Optimized control strategies for variable speed machines", Proc. 22nd IAHR Symp. Hdraulic Mach. Syst., Stockholm, Sweden, Jun. 29 - Jul. 2, 2004, Paper A15-2, pp. 1-9.

[7] I. Boldea, "Variable speed generators", CRC Press, Taylor \& Francis Edition, 2006

[8] Y. Pannatier, B. Kawkabani, C. Nicolet, J.-J. Simond, A. Schwery, P. Allenbach, «Investigation of Control Strategies for Variable-Speed Pump-Turbine Units by Using a Simplified Model of the Converters», IEEE Transactions on Industrial Electronics, Volume 57, Dec, 2009.

[9] C. Nicolet, B. Greiveldinger, J.-J. Herou, B. Kawkabani, P. Allenbach, J.-J. Simond, F. Avellan, "High-Order Modeling of Hydraulic Power Plant in Islanded Power Network", IEEE Transactions on Industrial Electronics, Volume 22, Nov, 2007.

[10] R. Babau, I. Boldea, T.J.E Miller, N. Muntean, “Complete Parameter Identification of Large Induction Machines From No-Load Acceleration-Deceleration Tests", IEEE Transactions on Industrial Electronics, Volume 54, Aug, 2007.

[11] A. Wechsler, G. Perugini, A. Schwery, J.M. Guerin, G. Lloyd, B. Kawkabani, «The development of a novel rotor protection for large doubly-fed induction machines», ICEM 2014 - International Conference on Electrical Machines, Berlin, Germany, Sept 2-5, 2014.

[12] A. Hodder, "Double-fed asynchronous motor-generator equipped with a 3-level VSI cascade", Thesis $n^{\circ} 2939$, Ecole Polytechnique Fédérale de Lausanne, 2004.
[13] Y. Pannatier, B. Kawkabani, C. Nicolet, A. Schwery, J.-J. Simond, "Start-up and Synchronisation of a Variable Speed Pump-Turbine Unit in Pumping Mode", ICEM 2010 - XIX International Conference on Electrical Machines, Rome, Italy, Sept 6-8, 2010.

[14] A. A. Arkadan, V. Rossillo-Johnson, N. A. Demerdash, "A DC-AC Inverter-Induction Motor System Network Model Compatible with Commonly Known Network Analysis Software Packages", Applied Power Electronics Conference and Exposition, APEC' 89, Conference Proceedings, Fourth Annual IEEE, Baltimore, MD, Mar 13-17, 2006.

[15] R. Karthigaivel, N. Kumaresan, M. Subbiah, "Performance predetermination of single-phase induction motors using Thevenin's, Norton's and Maximum power transfer theorems", Computer Communication and Informatics (ICCCI), Coimbatore, Jan. 8-10, 2015.

[16] Y. Pannatier, B. Kawkabani, C. Nicolet, A. Schwery, J.-J. Simond, «Optimization of the Start-up Time of a Variable Speed Pump-Turbine Unit in Pumping Mode», ICEM 2012 - XX International Conference on Electrical Machines, Marseille, France, Sept 2-5, 2012.

[17] J. W. Umland, M. Safiuddin, "Magnitude and Symmetric Optimum Criterion for Design of Linear Control Systems: What Is It and How Does It Compare with the Others?", IEEE Transaction on Industry Application, Vol 36, №3, May/June 1990.

\section{BIOGRAPHIES}

Timothé Maendly got his master degree in electrical engineering with energy specialization at the EPFL (Ecole Polytechnique Fédérale de Lausanne) in 2015 . He is currently partially working as a teaching assistant in the field of electrical machines and drives at the EPFL.

André Hodder (M'09) graduated in electrical engineering in 1999 and got his doctoral degree in 2004 both from EPFL, Ecole Polytechnique Fédérale de Lausanne. Since 2005 he is a lecturer and a researcher in the field of electrical machines, drives and their DSP control, pump-turbine plants and power system.

Basile Kawkabani (M'00-SM'11) received his master degree in 1978 from SUPELEC, Ecole Supérieure d'Electricité in Paris France, and his $\mathrm{PhD}$ degree in 1984 in Electrical Engineering from the Swiss Federal Institute of Technology in Lausanne (EPFL). From 1992 to 2010, he was lecturer and research associate at the EPFL Electrical Machinery Laboratory. He is currently a senior scientist in STI Scientists Group (Electrical Machinery - EPFL), and senior member of the IEEE. His interests include modeling of power systems, power system stability and control. 